\title{
An Advance Methodology for Hybrid Modeling and Selection of Grid Integrated Renewable Energy [Wind/Solar] Profile through Proteus
}

\author{
Prashant, Anwar Shahzad Siddiqui, Abhinav Saxena, Satyam, Vidushi, Shikha
}

\begin{abstract}
This paper shows the synchronization of grid integrated renewable energy and conventional sources feeding a load centres using proteus. The certain factor like variation in solar radiation, wind and load demand has been taken into consideration. The most challenging task during synchronization is selection of particular generating sources. In this Paper, Experimental hybrid modelling of grid integrated renewable energy projects (wind, solar) and conventional supply source has been performed. The experimental result verified on simulation platform proteus software through Arduinouno microcontroller. The output of system confirms the selectivity of particular energy source as per requirement of changing in the load demand and environmental conditions.
\end{abstract}

Index Terms: hybrid, modelling, proteus, modelling, solar, wind.

\section{INTRODUCTION}

In today's expeditiously and randomly developing technical era, eventual requirement for fruitful existence of human race is electricity. Several methodologies could be adopted in order to store, amplify or convert the electrical energy for the future use. To have an effective understanding of the electric energy and its sources, several theories are given and are required to be discussed for the sustainable use of the energy [1],[2],[3]. The energy sources are divided into three main categories where first is fossil fuels, second is renewable sources and third is nuclear sources. Coal, natural gas and petroleum are counted under fossil fuels. Hydroelectricity, solar and wind power are counted under resources of renewable energy. Apart from these fusion and Fission are considered as nuclear-powered sources of energy. Out of these, the most abundant and convenient are solar and wind energy [4],[5]. As the earth receives an inexhaustible and incredible supply of solar radiation and has an average wind velocity ofabout $20-25 \mathrm{~ms}^{-1}$. So, we are using these two sources for the generation of power. The most powerful energy sources which are considered to serve the large areas and capacities are solar and wind [6],[7]. This paper includes Simulation and selection of supplies from sources done by

Revised Manuscript Received on July 5, 2019

Prashant, Department of EE Jamia Millia Islamia, New Delhi, India.

Anwar Shahzad Siddiqui, Professor in Department of EE, Jamia Millia Islamia, New Delhi, India

Abhinav Saxena, Department of EE,JSSATE Noida, , India

Satyam, Electrical Engineering, JSSATE, Noida, India

Vidushi, Electrical Engineering, JSSATE, Noida, India

Shikha, Electrical Engineering, JSSATE, Noida, India
Arduino Uno in Proteus software. Proteus is one of the most reliable software for simulation. Whenever Solar and wind energies are insufficient for load demand conventional supply is used [8],[9],[10].

\section{SOLAR PV ARRAY}

Photovoltaic array is a linked collection of PV modules. The smallest element in this is photovoltaic cell which converts solar radiation into electricity [11],[12]. PV cell is basically a semi-conductor diode working on photoelectric effect. To generate maximum power 36 to $72 \mathrm{PV}$ modules are formed by connecting cells in parallel or in series [13]. Figure 1 shows the photovoltaic system and its basic circuit configuration. The "four parameters model" reflects the circuit diagram of PV system, and contains series resistance, current source, parallel resistance, and a diode [14],[15]. The light generated in the solar cell is represented through current source, $p-n$ junction's non-linear impedance is represented through diode, internal electrical loses are represented through series resistance and the leakage current to the ground is corresponded by shunt resistance. ${ }^{[3]}$ The light generated current source and diode are connected in anti-parallel way and reflects solar cell's ideal theoretical model.The falling of the solar radiation on the cell and the direct current generated are varied accordingly.[16],[17]

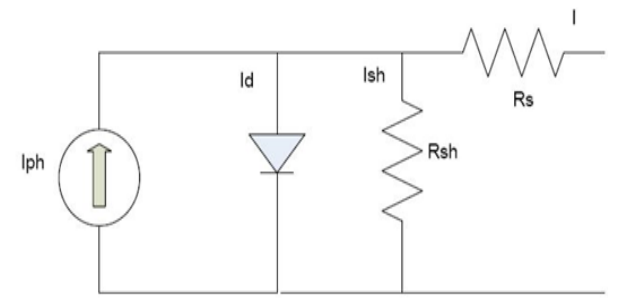

Fig.1. Photovoltaic cell (Basic circuit diagram)

According to the photovoltaic panel's circuit diagram as shown in figure 1, the characteristic equation is formed.

On applying KCL, the output current could be calculated as: $I=I p h-I d-I s c$

Due to the variance in temperature and irradiance, the light generated current also varies and the relation could be expressed through below mathematical equation [18].

$$
I=I p h-I s\left[\exp \frac{[V+I R s] q}{a k T N s}-1\right]-\frac{V+I R g}{\text { Ish }}
$$

$I p h=\operatorname{Ir} \frac{I s e}{I r 0}$ 


$$
I s=I s c /\left[\exp \left(\frac{V s c}{a V t}\right)-1\right]
$$$$
I d=I s\left[\exp \left(\frac{V+I R s}{a V t}\right)-1\right]
$$

$$
I s h=(V+I R s) / R s h
$$

$V t=\frac{\mathrm{kTNs}}{q}$

The relation between the current and the voltage in a photovoltaic module could be described through these expressions.

Series connected cells is represented by ' $\mathrm{Ns}$ '

Light generated current is reflected by 'Iph'

Reverse saturation current denoted by 'Is'

Series , Parallel resistances of the cells are represented by 'Rs' and 'Rsh' respectively

' $\mathrm{q}$ ' stand for electron charge, which is $1.60217646 \times 10^{-19} \mathrm{C}$ Constant of Boltzmann's value is represented through ' $\mathrm{K}_{\mathrm{T}}$ ' equal to $1.380 \times 10^{-23} \mathrm{~J} / \mathrm{K}$ and

Factor of Ideality under Modification is represented through 'a'.

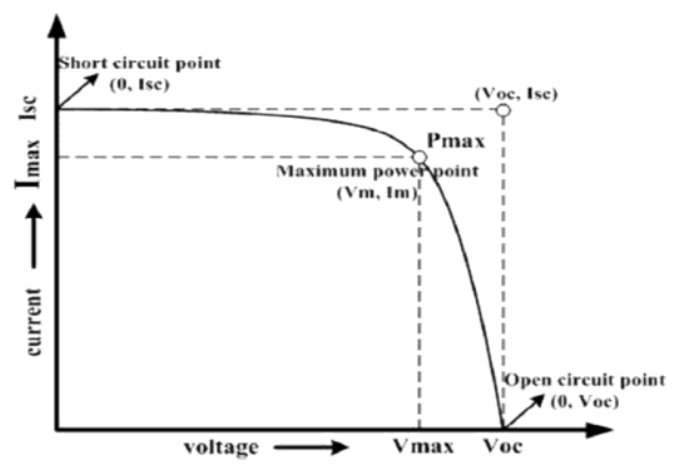

Fig.2 PV Cell I-V attibutes

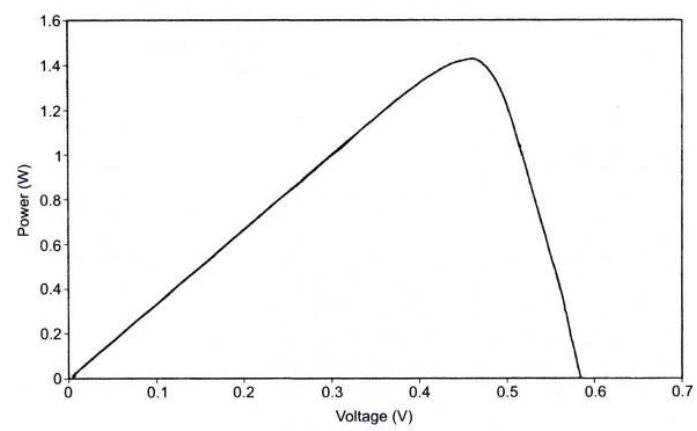

Fig.3: P-V Graph of PV module

With validation of mathematical statements, current-voltage and power-voltage attributes are depicted as expressed in fig 2 and 3 respectively[19].

Eq. (7) is extended from Eq. (8) to Eq. (17) for selection of solar PV array parameters.

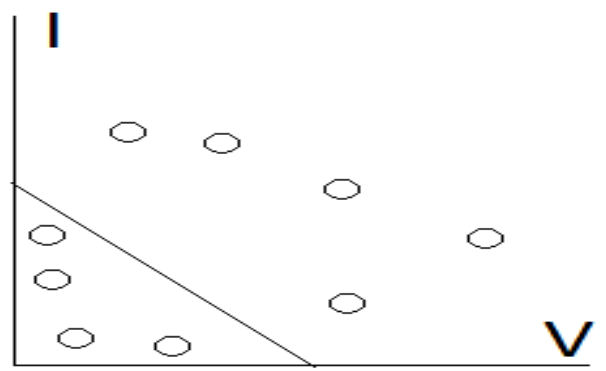

Fig.4 Diverging Regression analysis of solar I-V characteristics

$I=I p h-I d-I s c$

$I=I p h-I s\left[\exp \frac{(V+I R s) q}{a K T N s}-1\right]-\frac{V+I R s}{R s h}$

$\rightarrow I p h=\frac{I r I s c}{\operatorname{Iro}}$

$I=\frac{I r I s c}{\operatorname{Iro}}-\frac{I s c}{\left(\exp \frac{V o c}{a V t}-1\right)}-\frac{V+I R s}{R s h}$

$I=\frac{I r I s c}{I r o}-\frac{I s c}{\left(\exp \frac{V o c}{a V t}-1\right)} \cdot\left(\frac{\exp (V+I R s) q}{r K T N s}\right)-\frac{V+I R s}{R s h}$

$I\left[1+\frac{R s}{R s h}\right]=I s c\left[\frac{I r}{\operatorname{Iro}}-\frac{\left(\frac{\exp (V+I R s)}{r K T N s}-1\right)}{\left(\exp \frac{V o c}{r V t}-1\right)}\right]$

$\frac{I}{I s c}=\frac{\left\lfloor\frac{\operatorname{lr}}{\operatorname{Iro}}-\frac{\left(\frac{\exp (V+I R s)}{r K T N s}-1\right)}{\left(\exp \frac{V o c}{r V t}-1\right)}\right\rfloor}{\left(1+\frac{R s}{R s h}\right)}$

$\frac{I}{I s c}=\frac{I r}{I r o}-\frac{\frac{(V+I R s) q}{r K T N s}}{\left(\frac{V o c}{r V t}\right) /\left(1+\frac{R s}{R s h}\right)}$

$\frac{I}{I s c}=\frac{I r}{\text { Iro }}-\frac{(V+I R s)}{\text { Voc }}$

$I=\frac{I r}{I r o} I s c-\frac{I s c}{V o c}(V+I R s)$

$I\left[1+\frac{I s c R s}{V o c}\right]=\frac{I r I s c}{\text { Iro }}-\frac{I s c V}{V o c}$

$A\left[\frac{\frac{I}{\text { IrIsc }}}{1+\frac{\text { Isc }}{\text { Voc }}}\right]+B\left[\frac{V}{\frac{V o c}{\text { Isc }}\left(\frac{\text { Ir Isc }}{\text { Iro }}\right)}\right]=1$ 


$$
\frac{I}{A}+\frac{V}{B}=1
$$

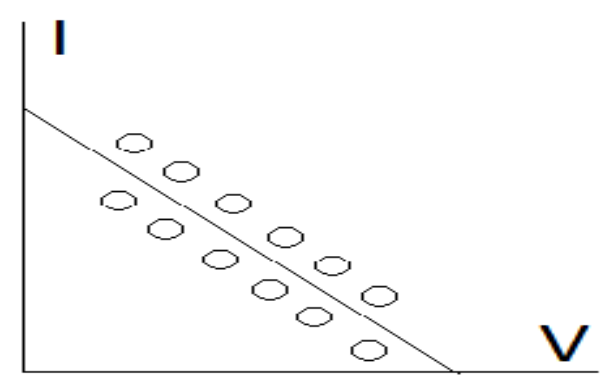

Fig.5. Converging Regression analysis of solar I-V characteristics

Selection of parameters of solar PV array depends on the I-V characteristics as shown in Fig.4 \& Fig.5. Both Figures are plotted from Eq. (17). Fig.4 shows the diverging nature of I-V characteristics while Fig.5 shows the converging nature. Hence selection of parameters of solar PV array will be decided by Fig. 5

\section{WIND TURBINE}

Wind turbine uses natural air flow for mechanical power generation to turn electric generators. Newly advanced vertical turbines are able to maximize efficiency with different rotor blades alignments producing about $230 \mathrm{~V}$ supply with air velocity of $20 \mathrm{~m} / \mathrm{s}^{2}$.In the converted mechanical energy, the magnitude completely relies on wind velocity and air density. Below equation is used to calculate the generated wind power:

$P m=\frac{1}{2} C_{p}\left(\lambda_{2} \beta\right) \rho A \omega^{a}$.

Where $\mathrm{Cp}=$ coefficient of power depends on $\beta, \lambda$

$\rho$ denotes denseness of air mass $\mathrm{kg}$ per $\mathrm{m}^{3}$.

A equates swept space by rotor blade in $\mathrm{m}^{2}$.

$\lambda$ is rotor blade with corresponding wind tip-velocity ratio $\beta$ reflects the rotor blade pitch angle in degrees

Fraction of kinetic energy modified into rotational energy through wind rotor coil, power coefficient represented as $\mathrm{Cp}$ and is bonded with the tip speed ratio represented as $\lambda .^{[7]}$

For the calculation of the output torque ${ }^{\mathrm{TM}_{\mathrm{O}}}$ f Wind turbine, the below equation could be used:

$T m=\frac{1}{2} \rho A C p \frac{\omega}{\lambda} \ldots$

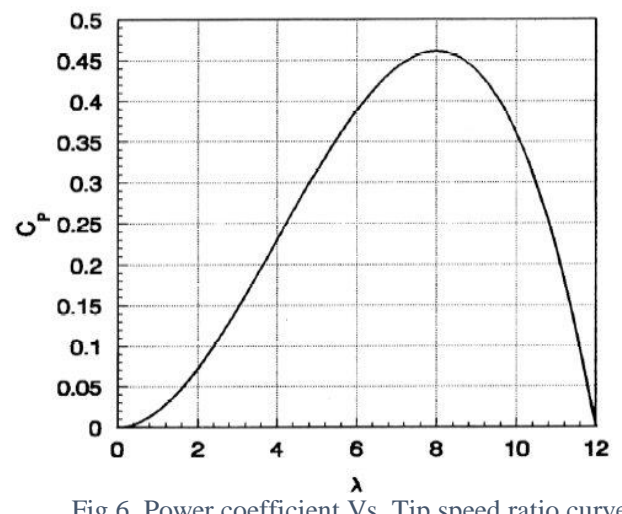

\section{MODELLING AND ANALYSIS}

The modelling and analysis of grid integrated hybrid system shows its execution through flowchart, hybrid model, controlling of Solar PV Array and wind turbine.

\section{A. Flowchart for Execution of Designed Model}

The given below flowchart shows the sequence of steps which are followed for obtaining the optimized solution for he selection of right portfolio of power producing source in line with the unforeseen variation in climate situations and load.

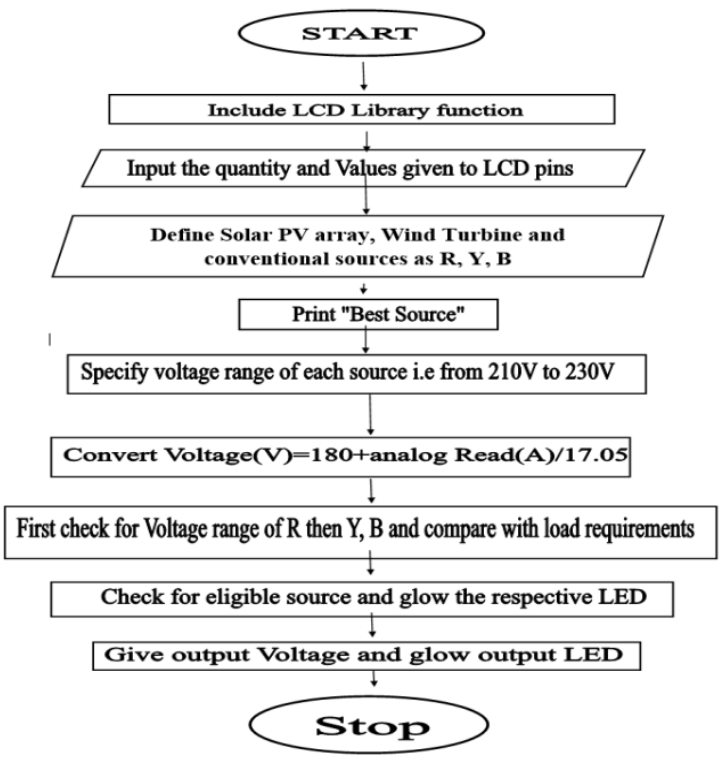

Fig.7. Flowchart for execution of model

\section{B. Hybrid Model}

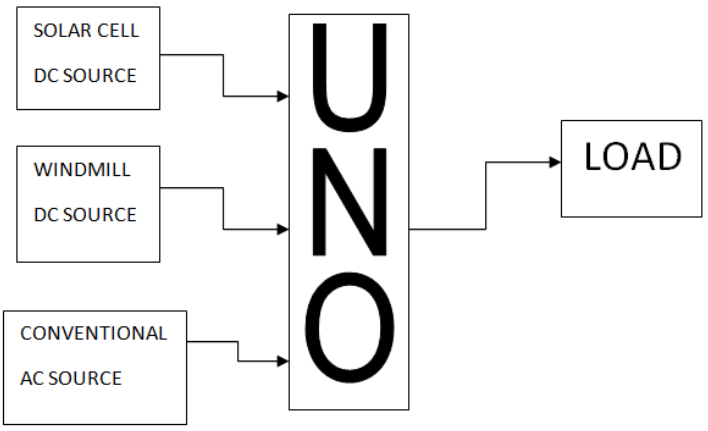

Fig.8.Block diagram of Hybrid Model

The designing \& simulation of hybrid modelin proteus software is shown in Fig.7,8. It is given the three supply sources solar, wind and conventional.All the supplies are synchronized to the same frequency and then compared for selection according to the load requirements and variation in environmental conditions.Here the load variation voltage boundary is between $210-230$ Volts. ${ }^{[8]}$ 


\section{Controlling of Solar PV array}

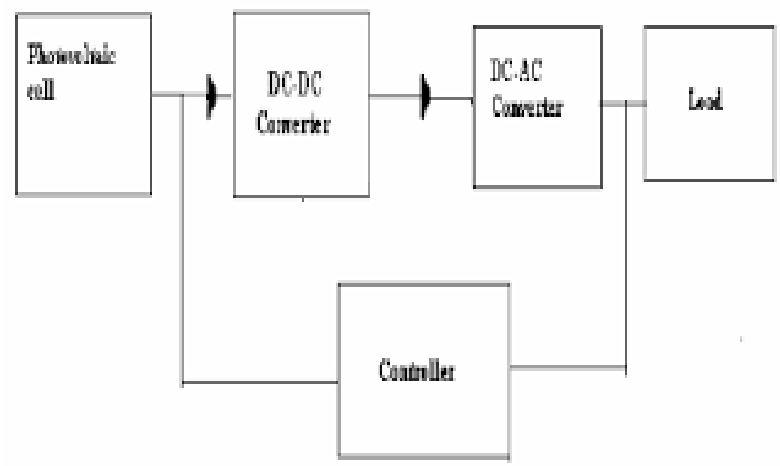

Fig.9. Block diagram of Solar PV Array control

The first priority is given to Solar energy so that it is selected and the LED D1 is glown when $\mathrm{R}$ is in range of (210-230) $\mathrm{V}$,provided sufficient intensity of solar radiation. For a particular constant load, temperature in centigrade is calculated. This will be known as threshold temperature. If the temperature of solar cell is more than or equal to threshold temperature than solar will act as a primary source else it will not be liable to act as source portfolio. ${ }^{[9]}$

\section{Controlling of Wind Turbine}

If solar PV array fails to act as primary source provided the intensity of solar radiation is not sufficient, then for a particular constant load, wind velocity in metre per second is calculated. This will be known as threshold velocity. If the velocity of wind flowing is more than or equal to threshold value than wind turbine will act as a primary source. ${ }^{[10]}$

So, the second priority is given to wind energy and it is selected when LED D2 is glown in which Y should be in range of (210-230) $\mathrm{V}$ which is chosen when the wind speed is in range to satisfy the load demand.

\section{E. Beyond Voltage Range of Solar PV Array and Wind Turbines.}

Sometimes due to environmental conditions or sudden increase in load demand sun PV array including wind turbine remains insufficient to fullfill load requirements, then conventional source becomes the primary supply.

The last priority is given to Conventional Source if both the systems are not able to satisfy load needs, then the logic is such designed such that then only Grid Energy will be used. It also provides great amount of energy at a significant cost

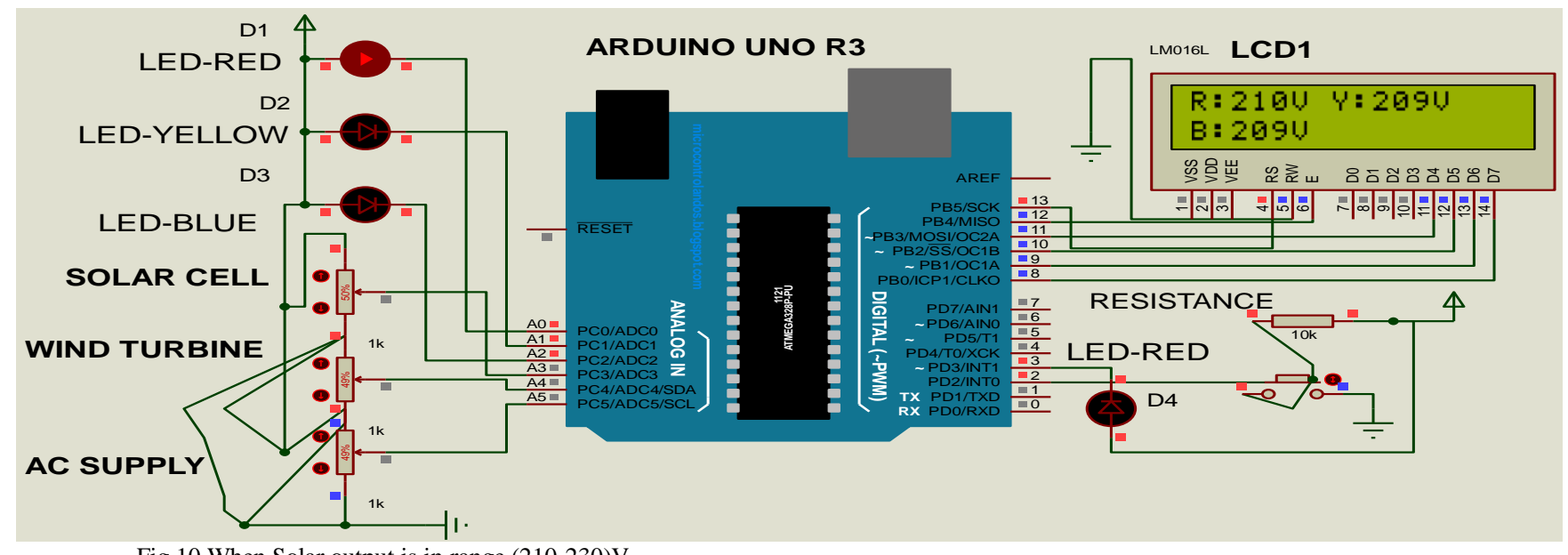

Fig.10 When Solar output is in range (210-230)V

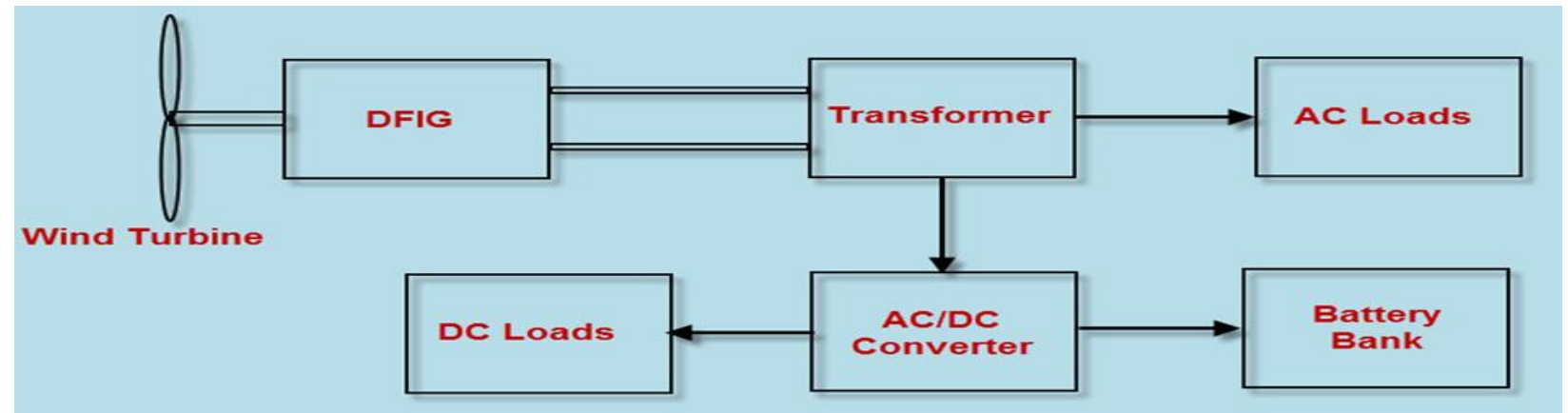

Fig.11. Block diagram of control of wind turbine 


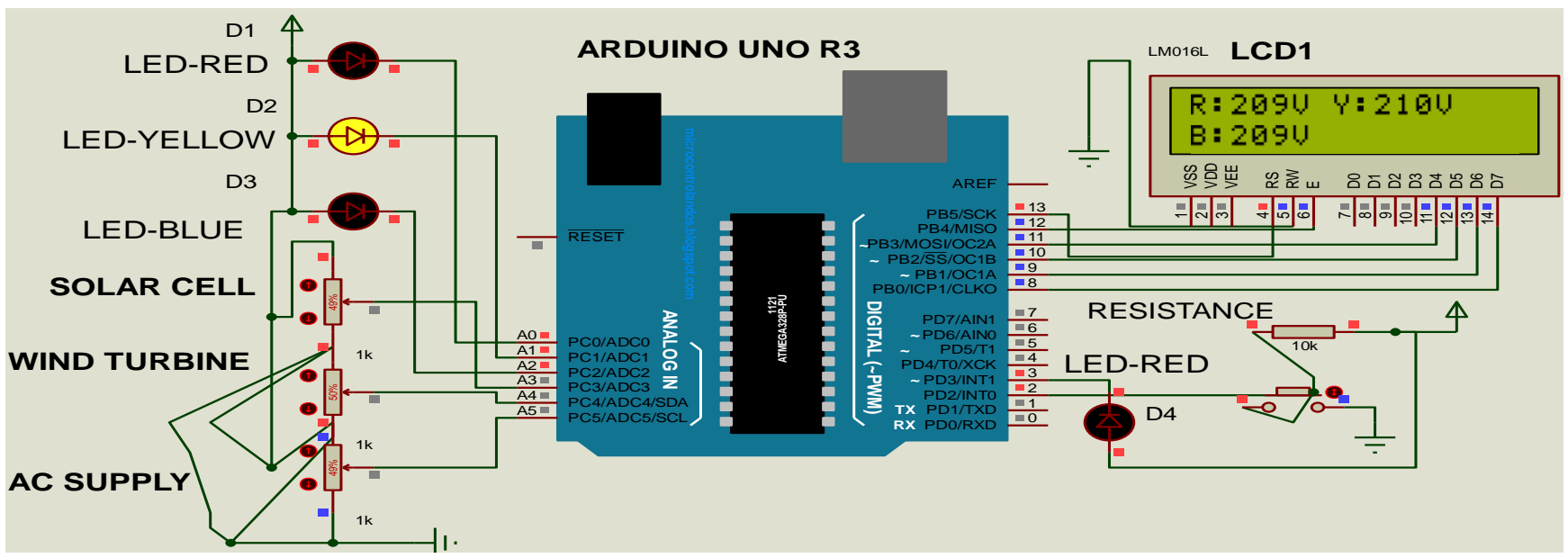

Fig.12.When Wind output is in range (210-230)

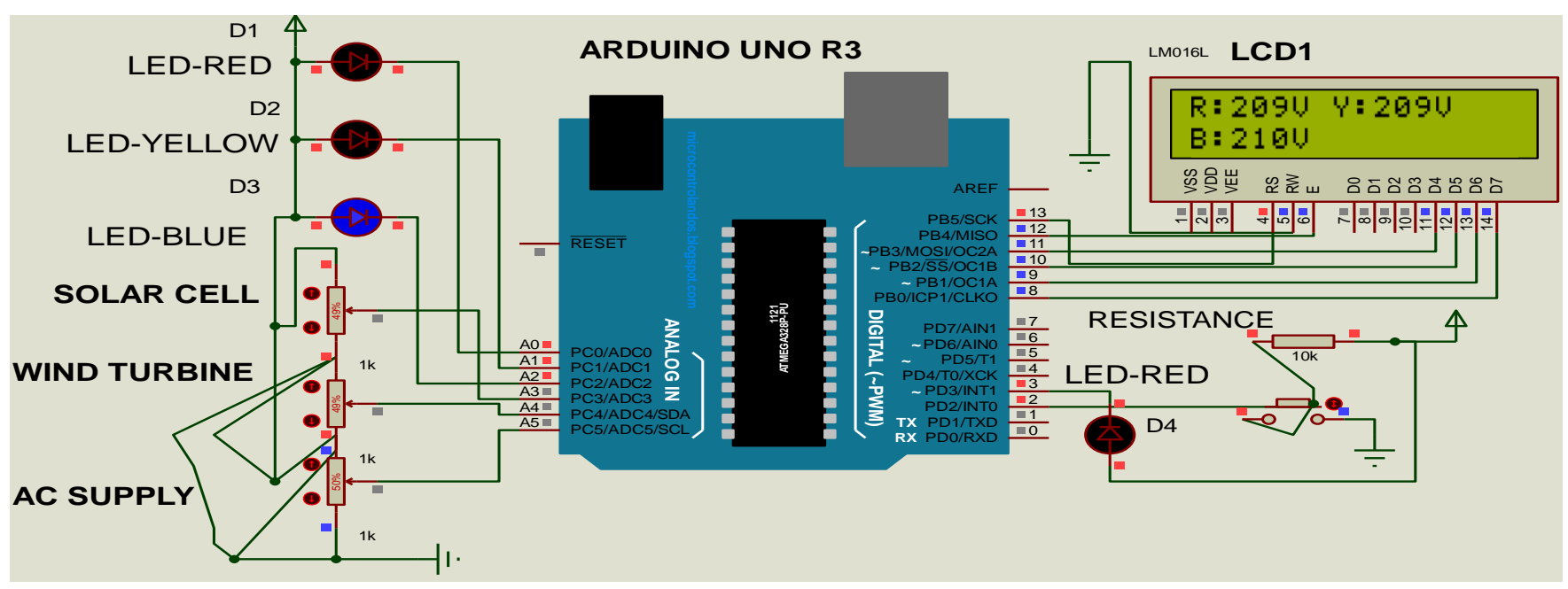

Fig.13. When AC Supply output is in range (210-230)

\section{F. Structure of Arduinouno Microcontroller}

LED- Digital pin 13 run corresponding LED. It is on when the pin goes high and vice-versa.

VIN Arduino controller input voltage pin when powered by external supply.

$5 \mathrm{~V}$ : A regulated $5 \mathrm{~V}$ derived through this pin through regulator on the adjoining board.

3V3: Regulator at board generates $3.3 \mathrm{~V}$ and current drawn equates 50 milliamperes.

Reset: Featured as a reset pin to shield used on board for blocking one.

Apart from this, a few pins have specified features:

Serial / UART: pins 0 for reception \& 1 for transmission of TTL sequential information and associated to analogus pins of ATmega8U2 usb toTTL successive chip.

GND pins for ground connection..

IOREF maintains voltage reference leading to microcontroller operation.

External Interrupts featured by pins $2 \& 3$ configured to set off interrupt upon any deviation from the specified information. PWM attributed by pins $3,5,6,9,10, \& 11$ which administer the output of PWM which consist of 8-bit information \& its corresponding to analog write() command. 10 no. pin of (SS), 11 no. of pin of (MOSI), 12 no. of pin of (MISO), 13 no. of pin of (SCK) uphold SPI conversation implementing SPI library.

Interfacing of Two Wire system using pin A4 or pin SDA pin features TWI conversation implementing wire library. AREF featuring reference value of analog voltage for corresponding inputs. As per diagram all the energy sources connected to the analogue gate of the Arduino processor via series diode and capacitor fiter circuit. Output from the source is connected to the analogue port via variable resisitor. We use variable resisitor to adjust the input voltage for calibration..Arduino runs on 5 volt DC voltage , so we use step down transformer with rectifier circuit. Load is connected across the pin no 3 via relay driver circuit. Here we use 2 by 16 lcd display to display the detail of different source. 


\section{An Advance Methodology for Hybrid Modelling and Selection of Grid Integrated Renewable Energy [Wind/Solar] Profile Through Proteus}

\section{V.CONCLUSION}

This paper shows the selection of particular generating unit with the load demand requirement at different instance. The first preference is given to portfolio of solar energy project under the given sufficient intensity of solar radiation which fullfill demand of the energy. The next priority is given to wind energy profile under the optimal wind speed which satisfy the load demand. Alternatively, when the environmental conditions are not favourable to complete the demand of load through renewable energy sources immediately system is switch over to the conventional source. The simulation results also verified the experimental results which fulfil the load demand according to the unforeseen variation in environmental situations and load. The given system involving the different generating units shows the reliable, efficient outputs with the robust nature of output with the variation in the internal parameters of the inputs.

\section{REFERENCES}

1. Yu wang,YinxingShen,Shiwen Mao, "Adaptive Learning Hybrid Model for Solar Intensity Forecasting",IEEE transactions on industrial informatics, vol.14, no.4, april, 2018.

2. Shekhanabi B Chalageri, Akash M Deshpande, Manjunath S Banad, Anoop S Pavate, Prof. SujataEresimi ", Generation of Electricity by Wind Tree" ISSN: 2350-0328 International Journal of Advanced Research in Science, Engineering and Technology Vol. 4, Issue 5, May 2017.

3. Ragunath L Senthilvel S. "Hybrid Energy Generation Through Vertical Axis Savonius Wind Turbine and Solar Panel" IJIRST -International Journal for Innovative Research in Science \& Technology, Volume 2 , Issue 11, April 2016.

4. Arjun A. K., Athul S., Mohamed Ayub, Neethu Ramesh, and Anith Krishnan, Micro-Hybrid Power Systems - A Feasibility Study. Journal of Clean Energy Technologies, Vol. 1, No. 1, January 2013. System Using Wind Energy and Solar Energy".International Journal of Scientific and Research Publications, Volume 5, Issue 3, ISSN 2250-3153, March 2015.

6. Mohammed Hadi Ali, "Experimental Comparison Study for Savonius International Journal of Modern Engineering Research (IJMER) www.ijmer.com Vol. 3, Issue. 5, pp-2978-2986 ISSN: 2249-6645, Sep - Oct. 2013.

7. MagediMohM.Saad, NorzelawatiAsmuin, "Comparison of horizontal axis wind turbines and vertical axis wind turbines"in IOSR journal of engineering, Volume 04, Issue 08,August 2014.

8. AshwinDhote,VaibhavBankar, "Design, Analysis and Fabrication of savonius vertical axis wind turbine" in International research journal of engineering and technology. Volume:02 Issue:03,June 2015.

9. N. Hatziargyriou, H. Asano, R. Iravani, and C. Marnay, "Clustering based improvement of nonparametric functional time series forecasting: Application to intra-day household-level load curves," IEEE Power Energy Mag., vol. 5, no. 1, pp. 411-419, Sep. 2014.

10. X. Fang, S. Misra, G. Xue, D. Buccella, and C. Yang, "Smart grid - The new and improved power grid: A survey," IEEE Commun. Surveys Tuts., vol. 14, no. 4, pp. 944-980, Dec. 2012

11. .W.T.Chong,"Performance investigation of a power augmented vertical axis wind turbine for urban high-rise application", Renewable Energy 51(2013)388-397.

12. https://etap.com/product/photovoltaic-array-solar-panel

13. Ashish S. Ingole, Bhushan S. Rakhonde, "Hybrid Power Generation System Using Wind Energy and Solar Energy".International Journal of Scientific and Research Publications, Volume 5, Issue 3, ISSN 2250-3153, March 2015.

14. T. Govindaraj , K. Bharanidharan," Stability and Reliability Improvement in Solar Wind Hybrid Power System with Battery Energy Storage Station", International Journal of Emerging Trends in Electrical and Electronics ,IJETEE ,ISSN: 2320-9569, Vol. 10, Issue.
5. $\quad$ Ashish S. Ingole, Bhushan S. Rakhonde," Hybrid Power Generation Wind Turbine of Two \& Three Blades At Low Wind Speed", 3, April-2014.

15. Mohamed Nfaoui Khalil El-Hami, "Extracting the maximum energy from solar panels “, Energy Reports, Vol 4, pp 536-545,November 2018.

16. W.T. Chong, "Performance investigation of a power augmented vertical axis wind turbine for urban high-rise application", Renewable Energy 51 (2013) 388-397.

17. Wei Qi, Jinfeng Liu, Xianzhong Chen, and Panagiotis D. Christo fides, "Supervisory Predictive Control of Standalone Wind/Solar Energy Generation Systems", IEEE Transactions on Control Systems Technology, Volume: 19, Issue: 1, Jan. 2011.

18. X. Fang, S. Misra, G. Xue, D. Buccella, and C. Yang, "Smart grid - The new and improved power grid: A survey," IEEE Commun. Surveys Tuts., vol. 14, no. 4, pp. 944-980, Dec. 2012.

\section{AUTHORS PROFILE}

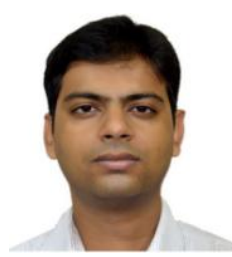

Mr. Prashant is PhD scholar at Department of Electrical Engineering, Jamia Millia Islamia, New Delhi. His research areas include Power System, Restructuring and Deregulation of Power System, Solar Photovoltaic Systems, Renewable Energy, $\&$ application of intelligent techniques in power system operations.

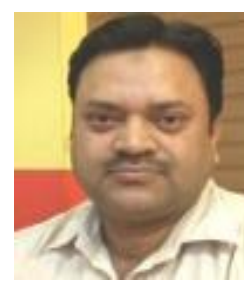

Dr. Anwar Shahzad Siddiqui is a Professor in the Department of Electrical Engineering, Faculty of Engineering and Technology, Jamia Millia Islamia (JMI), and has 24 years of teaching and research experience in the field of Power systems Control and Management. Dr. Anwar has done extensive research work in the broad area of Power System Control and Management, specifically on Congestion management in Deregulated Power System, FACTS Devices and Applications of Artificial Intelligence Techniques in the field of Power System. He has published many research papers in International Journals and Conferences of repute.

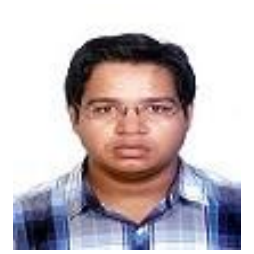

Mr.Abhinav Saxena received the B.Tech. Degree in Electrical Engineering from U.P.T.U Lucknow in 2011 and M.Tech.from IIT Roorkee in 2013.Currently he is pursuing Ph.D. in Electrical Engineering from Jamia Millia Islamia, India and working as Assistant Professor, Department of Electrical Engineering, JSSATE Noida. His research areas include Power Electronics, Electrical Machines, Power System, Control System and Intelligent Techniques, Renewable energy.

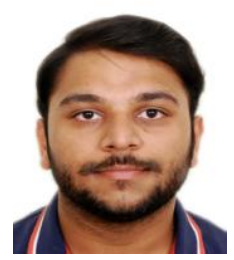

Mr. Satyam Bansal is persuing B.Tech in Electrical Engineering. His area of research include solar energy, wind energy and power system.

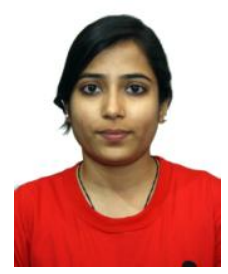

Ms Vidushi Jaiswal is persuing B.Tech in Electrical Engineering. Her research area includes power system analysis, solar photovoltaic systems and wind energy.

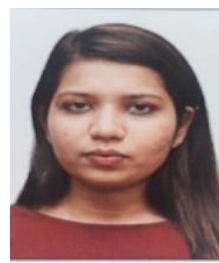

Ms Shikha Patel is persuing B.Tech in Electrical Engineering. Her research area includes renewable energy and power electronics.

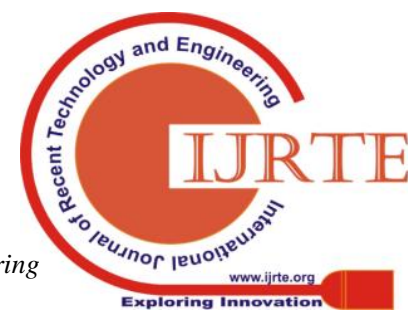

